\title{
Conocarpus Erectus Extract as an Eco-Friendly Corrosion Inhibitor for Aluminum in Hydrochloric Acid Solution
}

\author{
Abd El-Aziz S. Fouda 1,* (D), Amal H. Tilp 2, Ameena M. Al-Bonayan ${ }^{3}$ \\ 1 Department of Chemistry, Faculty of Science, El-Mansoura University, Egypt; asfouda @ hotmail.com (A.e.-A.S.F.); \\ 2 Chemistry Department, College of Science, Qassim University, Qassim, Buraydah, Saudi Arabia and Chemistry \\ Department, Faculty of Girls, Arts, Science and Education, Ain Shams University, Egypt; amalhemeda83@yahoo.com \\ (A.H.T.); \\ 3 Department of Chemistry, Faculty of Science, Umm Al-Qura University, Makkah, Saudi Arabia; benayana@ hotmail.com \\ (A.M.A.B.); \\ * Correspondence: asfouda@hotmail.com;
}

Scopus Author ID 56231506400

Received: 20.09.2020; Revised: 18.10.2020; Accepted: 20.10.2020; Published: 25.10.2020

\begin{abstract}
Conocarpus Erectus extract was examined as a green corrosion inhibitor for $\mathrm{Al}$ in $1 \mathrm{M} \mathrm{HCl}$ and evaluated by different methods (chemical \& electrochemical methods). Surface checks were used to illustrate the importance of this green extract to Al's corrosion inhibition process. The inhibition efficiency (\% IE) increased with the raising of both Conocarpus Erectus extract dose and temperature, indicating that this extract was adsorbed chemically on Al surface. The \%IE was $91.1 \%$ when the concentration Conocarpus Erectus extract was 300 ppm. Conocarpus Erectus extract inhibits both anodic and cathodic reactions, so it is a mixed kind inhibitor. The \%IE of Al occurs by the adsorption process, and this metal is subject to the adsorption, according to Temkin isotherm. The surface examination was detected by utilizing a scanning electron microscope (SEM). The outcome data obtained from all experimental studies are excellent and proved the effectiveness of Conocarpus Erectus extract for Al's corrosion resistance.
\end{abstract}

Keywords: corrosion inhibition; Conocarpus Erectus; $\mathrm{HCl}$; aluminum; SEM.

(C) 2020 by the authors. This article is an open-access article distributed under the terms and conditions of the Creative Commons Attribution (CC BY) license (https://creativecommons.org/licenses/by/4.0/).

\section{Introduction}

Aluminum is the second widespread and abundant element in the Earth's crust after iron. The importance of $\mathrm{Al}$ metal and its alloys due to its multiple applications in several fields of industries as the food industry, electronic devices, building, and transport [1]. Many acidic solutions such as $\mathrm{HCl}, \mathrm{H}_{3} \mathrm{PO}_{4}$, sulfamic, and $\mathrm{H}_{2} \mathrm{SO}_{4}$ are extensively used in several techniques such as pickling of metals, cleaning of boilers, acidizing of oil wells, and recovery of ion exchangers [2]. In addition to the previous, $\mathrm{HCl}$ is one of the acids that are widely utilized in refining the productivity of wells in oil and gas production, and over numerous years is utilized to raise the primary productivity of new wells [4-5]. Plant extracts are used as a green corrosion inhibitor, which has a low cost and environment friendly. It is used to prevent corrosion of metal and alloys at different corrosion conditions. The search for green corrosion inhibitors has been active in the last two decades, and many plant extracts were investigated in connection with altered metals and corrosive environments. Some research has been highlighted on the positive application of plant extracts as corrosion protection for $\mathrm{Al}$ in a various acidic environment [6-8]. Certainly, occurring corrosion inhibitors are environmentally friendly, available, inexpensive, and sources for obtaining them are renewable [9-10]. Table 1 displays 
a summary of the main results achieved with the utilization of altered plant extracts as inhibitors for the dissolution of $\mathrm{Al}$ in altered acidic environments [11-21].

Table 1. List of plant sources utilized for dissolution inhibition studies.

\begin{tabular}{l|l|l|l} 
Extract & Metal/Medium & IE $(\%)$ & Ref. \\
\hline Capparis decidua fruit extract in ethyl alcohol & $\mathrm{Al} / \mathrm{HCl}$ & 32 & {$[11]$} \\
\hline Jasminum nudiflorum Lindl. leaf extract in ethanol & $\mathrm{Al}$ alloy/ $\mathrm{HCl}$ & 45.5 & {$[12]$} \\
\hline Chrysophyllum albidum fruit extract in ethanol & $\mathrm{Al}$ alloy/ $\mathrm{H}_{2} \mathrm{SO}_{4}$ & $58-90$ & {$[13]$} \\
\hline Coconut coir dust extract in acetone & $\mathrm{Al} / \mathrm{HCl}$ & $18-80$ & {$[14]$} \\
\hline Cola acuminata fruit extract in ethanol & $\mathrm{Al} / \mathrm{H}_{2} \mathrm{SO}_{4}$ & $8-46$ & {$[15]$} \\
\hline Nicotiana extract in ethanol & $\mathrm{Al} / \mathrm{H}_{2} \mathrm{SO} \mathrm{O}_{4}$ & $4-45$ & {$[15]$} \\
\hline Alcoholic extract of Phoenix dactylifera plant & $\mathrm{Al}$ and $\mathrm{Al} / \mathrm{Si}$ in $\mathrm{HCl}$ & 91.8 & {$[16]$} \\
\hline Camellia Sinensis (green tea) & $\mathrm{Al}$ alloy/HCl & 80.0 & {$[17]$} \\
\hline Solanumtrilobatum leaves & $\mathrm{Al} / \mathrm{NaOH}$ & 94.0 & {$[18]$} \\
\hline Morindacitrifolia. $L$ & $\mathrm{Al} / \mathrm{HCl}$ & 90.0 & {$[19]$} \\
\hline Ziziphus mauritiana fruit & $\mathrm{Al}$ and $\mathrm{Cu} / \mathrm{HCl}$ & 76.8 & {$[20]$} \\
\hline Alcoholic Lawsonia inermis leaves & $\mathrm{Al} / \mathrm{HCl}$ & 66.8 & {$[21]$}
\end{tabular}

In this present research, we studied the environmentally friendly materials Conocarpus Erectus extract as an inhibitor for $\mathrm{Al}$ dissolution in a $1 \mathrm{M} \mathrm{HCl}$ solution. Several methods have been used to study the inhibition behavior, including electrochemical and mass loss studies. Also, the surface analysis of Al was done by SEM.

\section{Materials and Methods}

\subsection{Materials.}

The Al metal samples used in chemical studies and surface analysis were cut in a square shape used, and their dimensions were $(2 \times 2 \times 0.2 \mathrm{~cm})$ with a purity of $99.98 \%$. About electrochemical corrosion, the working rods were prepared in $1 \times 1 \mathrm{~cm}$ dimensions and welded with copper wire from one side and put it inside a glass tube and surrounded by epoxy, and placed for 24 hours to adhere well. The samples used are mechanically sanded with altered degrees of silicon carbide sheets (320-2000), washed with double distilled water, and then dried.

\subsection{Chemicals}

2.2.1. Preparation of plant extract.

Fresh aerial parts of Conocarpus Erectus extract sample were obtained and dried in an oven at $80^{\circ} \mathrm{C}$. After this step, we crushed it and converted it into powder. "The powdered $(250$ g) were dripping in $500 \mathrm{ml}$ of dichloromethane for five days and then imperiled to repeated extraction with $5 \times 50 \mathrm{ml}$ until fatigue of plant materials. The extracts found were then concerted utilizing rotary evaporator at a temperature under $323 \mathrm{~K}$ ". Finally, the dichloromethane is evaporated to obtain solid Conocarpus Erectus and stored at room temperature and ready for utilizing as corrosion protection in the research. 


\subsubsection{Solutions}

The used hydrochloric acid was prepared from $37 \%$ hydrochloric acid using double distilled water. Using the prepared $\mathrm{HCl}$, different solutions including $1 \mathrm{M} \mathrm{HCl}$ were prepared, without or by adding different doses of Conocarpus Erectus ranging from 50 to 300 ppm.

\subsection{Techniques utilized for determining inhibition efficiency.}

\subsubsection{Weight loss (WL) technique.}

The coins dimension for the WL tests was $2 \times 2 \times 0.2 \mathrm{~cm}$. "The surface of these coins was scratched by altered grades of emery sheets, washed and degreased in the alkaline mixture $\left(15 \mathrm{~g} \mathrm{Na}_{2} \mathrm{CO}_{3}+15 \mathrm{~g} \mathrm{Na}_{3} \mathrm{PO}_{4} / \mathrm{L}\right)$, washed with double distilled water, dried, weighed, and put them in solutions prepared from altered concentrations of Conocarpus Erectus from 50 to 300 $\mathrm{ppm}$. This occurs in the presence of $1 \mathrm{M} \mathrm{HCl}$ to compare with a sample that was placed in a solution of $1 \mathrm{M}$ hydrochloric acid with Conocarpus Erectus. Samples are left for half an hour in solutions. The samples are weighed and then placed again in their solutions [22]. The steps are repeated every half an hour until the final of the experiment reaches to 3 hours". The (IE\%) and the degree of $\mathrm{Al}$ coverage $(\theta)$ have been computed by the equation:

$$
\% I E_{w t}=\left[1-\frac{W}{W^{\circ}}\right] \times 100=\theta \times 100
$$

where $\mathrm{W}$ and $\mathrm{W}^{\circ}$ refers to the $\mathrm{WLs}$ of $\mathrm{Al}$ per unit area with and without the investigated Conocarpus Erectus extract, correspondingly.

\subsubsection{Electrochemical techniques.}

In this investigation, the electrochemical technique was used through a cell consisting of three classic electrodes, which is the working electrode that is studied. "This electrode consists of Al metal, where the method of preparation was explained earlier, and the surface area exposed in it is $1 \mathrm{~cm}^{2}$, and before using the electrode it is processed according to the test followed WL, the second electrode is the reference electrode, and the third electrode is the auxiliary electrode. For the working electrode, it is placed in the utilized solution at the opencircuit voltage for 30 minutes, where the stability condition is obtained. Polarization curves were recorded at a steady scan rate of $0.5 \mathrm{mV} \mathrm{s}^{-1}$ initially from $-0.8 \mathrm{~V}$ to $1.0 \mathrm{~V}$ (SCE). In this technique, the current density is a function of the calculation". For computing the $\left(\% I E_{p}\right)$ and $(\theta)$ the following formula was used:

$$
\% I E_{p}=\left[1-\frac{i_{\operatorname{corr}_{(i n h)}}}{i_{\text {corr }}(\text { free })}\right] \times 100=\theta \times 100
$$

where $i_{\text {corr(free) }}$ and $i_{\text {corr(inh) }}$ are the uninhibited and inhibited corrosion current density values, correspondingly.

Alternating current (AC) electrochemical impedance spectroscopy (EIS) measurements were acquired in the frequency range of $2 \times 10^{4} \mathrm{~Hz}$ to $8 \times 10^{2} \mathrm{~Hz}$ at rest potential by applying 10 $\mathrm{mV}$ at OCP. All the results of impedance were compatible with the appropriate equivalent circuit using the Gamry Echem program and by using the charge transfer resistance $\left(\mathrm{R}_{\mathrm{ct}}\right)$. The $\left(\% I E_{E I S}\right)$ and the $(\theta)$ were measured from $\mathrm{R}_{\mathrm{ct}}$ data utilizing the next eq.:

$$
\% I E_{E I S}=\left[1-\left(\frac{R_{c t}^{\circ}}{R_{c t}}\right)\right] \times 100=\theta \times 100
$$

where $R_{c t}$ and $R_{c t}^{o}$ are the charge transfer resistances for the inhibited and the inhibitor-free system from Conocarpus Erectus extract, correspondingly. 
Electrochemical frequency modulation (EFM) applied through two sinus waves from 2 to $5 \mathrm{~Hz}$. "This technology is fast and not destructive. Corrosion current density (icorr), causal factors $\mathrm{CF} 2$ and $\mathrm{CF} 3$, and Tafel slopes $\left(\beta_{\mathrm{a}}\right.$ and $\beta_{\mathrm{c}}$ ) were obtained through the greater peaks [23].

In the electrochemical investigation, the device used was Gamry Potentiostat/ Galvanostat / ZRA (PCI4-G750). Gamry includes DC105 software for polarization and EIS300 EIS program for EIS, the EFM140 program for EFM, as well as a computer for data collection". Echem Analyst version 5.5 was used to plot, calculate, and synthesize data. All electrochemical studies were applied at $298 \mathrm{~K}$.

\subsection{Surface analysis.}

The morphological properties of the Al surface were studied by utilizing SEM. This exam happens in $1.0 \mathrm{M}$ of $\mathrm{HCl}$ in the absence of a corrosion inhibitor Conocarpus Erectus extract and in the case of the highest dose of Conocarpus Erectus extract ( 300 ppm). Then, the coins were dipped in destructive environments at one day; the specimens were prepared quietly with double distilled water, dried, and mounted into the achieved examined test utilizing Japan, JEOL JSM-5500.

\section{Results and Discussion}

\subsection{Potentiodynamic polarization (PP) technique.}

$\mathrm{PP}$ curves were recorded for $\mathrm{Al}$ in $1 \mathrm{M} \mathrm{HCl}$ solutions with and without various doses of Conocarpus Erectus extract at 298 K, as shown in Fig. 1. "The polarization curves remain almost the same in the absence of the extract, but in the presence of extract, both anodic and cathodic branches shifted to the lower values of corrosion current densities compared to the blank solution but the shift towards more cathodic. The electrochemical parameters derived from the polarization curves in Fig. 1 are given in Table 2. It is noted from this Table that $i_{\text {corr }}$ values decrease with the increase of the dose of extract due to the increase in the blocked fraction of the Al surface by adsorption of extract components. The Tafel slopes of $\beta_{\mathrm{a}}$ and $\beta_{\mathrm{c}}$ at $298 \mathrm{~K}$ do not change remarkably upon the addition of Conocarpus Erectus extract, which indicates that both anodic and cathodic processes are controlled. A small shift in Ecorr values towards negative direction was obtained in the presence of the extract, indicating that the mixed nature of the extract". Generally, an inhibitor can be classified as a cathodic or anodic type if the shift of corrosion potential in the presence of the inhibitor is more than $85 \mathrm{mV}$ with respect to that in the absence of the inhibitor [24]. In our test indicates that Conocarpus Erectus extract can be arranged as a mixed-type inhibitor but more cathodic without changing in the mechanism of the corrosion process.

\subsection{Electrochemical impedance spectroscopy (EIS) technique.}

Figure 2 displays the Nyquist plots of the Al resulting from equivalent circuit measurements when there are different concentrations of Conocarpus Erectus extract. The matching circuit that defines for $\mathrm{Al}$ and electrolyte are established in Fig. 3; in this circuit, constant phase elements (CPE) are used as a substitute for capacitors to provide multiple types of homogenization that are not ideal for electrode corrosion; such as surface impurities and roughness, a decrease in polishing, and grain boundaries [25]. 


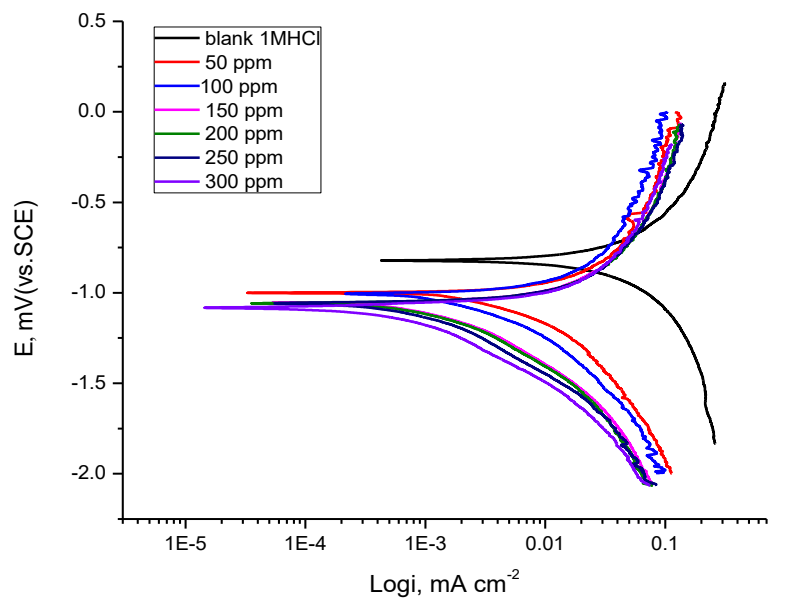

Figure 1. Tafel polarization diagrams for the dissolution of $\mathrm{Al}$ in $1 \mathrm{M} \mathrm{HCl}$ solution at various doses of Conocarpus Erectus at $298 \mathrm{~K}$.

Table 2. Parameters obtained from PP test for the dissolution of $\mathrm{Al}$ in 1 hydrochloric acid in the absence and presence of altered dose from Conocarpus Erectus at $298 \mathrm{~K}$.

\begin{tabular}{|c|c|c|c|c|c|c|c|}
\hline $\begin{array}{l}\text { [inh], } \\
\text { ppm }\end{array}$ & $\begin{array}{c}\mathbf{i}_{\text {corr, }} \\
\mathrm{mA} \mathbf{~ c m}^{-2}\end{array}$ & $\begin{array}{c}-E_{\text {corr, }} \\
\text { V vs SCE }\end{array}$ & $\begin{array}{c}\beta_{\mathrm{a}}, \\
\mathrm{mV} \text { dec }^{-1}\end{array}$ & $\begin{array}{c}\beta_{c}, \\
m V \operatorname{dec}^{-1}\end{array}$ & $\begin{array}{c}\text { C.R.x10-3 } \\
\text { mpy }\end{array}$ & $\theta$ & $\%$ IE \\
\hline Blank & 48.30 & 0.821 & 240 & 390 & 207.0 & ----- & ---- \\
\hline 50 & 2.440 & 1.000 & 83 & 287 & 10.48 & 0.949 & 94.9 \\
\hline 100 & 1.800 & 1.010 & 101 & 334 & 7.711 & 0.962 & 96.2 \\
\hline 150 & 0.815 & 1.050 & 61 & 304 & 3.494 & 0.983 & 98.3 \\
\hline 200 & 0.537 & 1.060 & 35 & 219 & 2.304 & 0.988 & 98.8 \\
\hline 250 & 0.400 & 1.060 & 34 & 233 & 1.714 & 0.992 & 99.2 \\
\hline 300 & 0.312 & 1.080 & 52 & 255 & 1.338 & 0.993 & 99.3 \\
\hline
\end{tabular}

Nyquist diagrams are designated by a semicircle loop. "These establish that a charge transfer process refers to the dissolution of Al metal. EIS parameters and $\% \boldsymbol{I E}$ were obtained and recorded in Table 3. The results were gained in the impedance data for $\mathrm{Al}$ in $1.0 \mathrm{M}$ hydrochloric acid with and without altered doses of Conocarpus Erectus extract. Fig. 2 shows the region of low frequency, and in the existence of Conocarpus Erectus extract, the impedance values rise compared to the absence of the Conocarpus Erectus extract, the radius of the circle rises when the dose of the Conocarpus Erectus extract increases and hence, the charge transfer resistance in corrosion reactions increases. From all the above, there is high resistance established as the result of adsorption of the Conocarpus Erectus extract at the interface $\mathrm{Al}$ /solution". The Al dissolution and the adsorbed Conocarpus Erectus inhibitor on the Al surface can be characterized by "n" parameter from EIS data [26]. The lowest data of " $n$ " (0.872) was detected for the sample immersed in $\mathrm{HCl}$ in the absence of the Conocarpus Erectus extract. This can be qualified to the surface inhomogeneity arising from the Al surface damage and the ununiformed corrosion attack". This can be clarified by the adsorption of Conocarpus Erectus molecules on the surface of Al causing in more uniform corrosion on the Al. The $\mathrm{C}_{\mathrm{dl}}$ was evaluated utilizing the following Eq.4 [27]:

$$
C_{d l}=Y_{o}\left(\omega_{\max }\right)^{n-1}
$$

Where $Y_{0}$ is the CPE magnitude, and " $n$ " is the variance CPE data of the: -1 ie $n$ ie 1 . Using equation 4. From Table 3 we note a lower in the values of $\mathrm{C}_{\mathrm{dl}}$ with an increase in the dose of Conocarpus Erectus extract, and this can be explained by a decrease in the local dielectric constant and / or an increase in the thickness of the electrical double layer [28]. This due to the adsorption of Conocarpus Erectus molecules on the Al/interface of solution and forming of a protective film on the interface of the Al solution". 


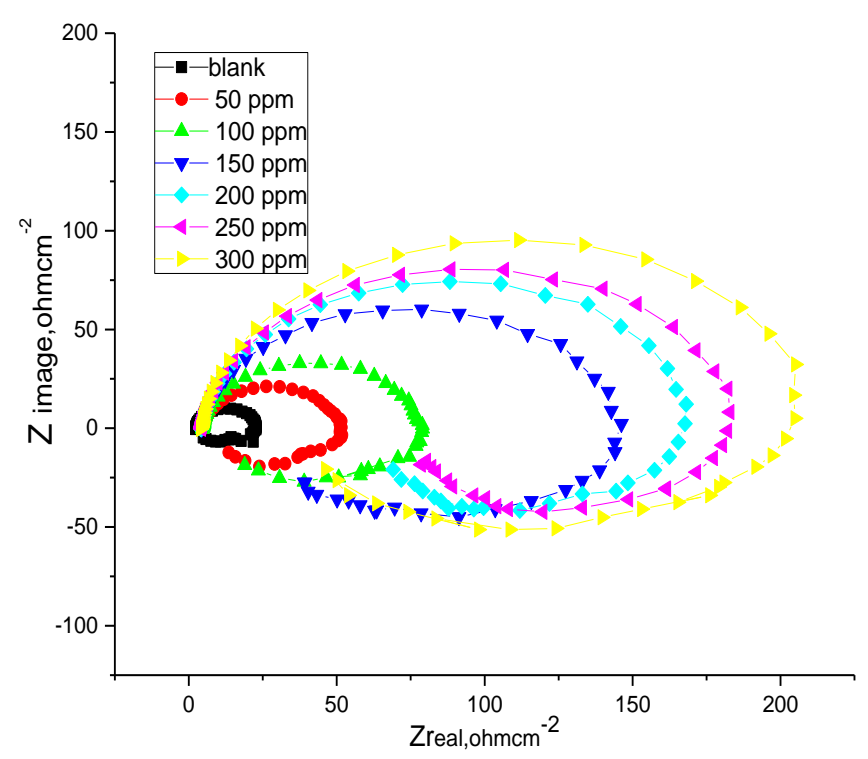

Figure 2. The Nyquist diagram for Al dissolution in existence and nonexistence of Conocarpus Erectus extract $298 \mathrm{~K}$

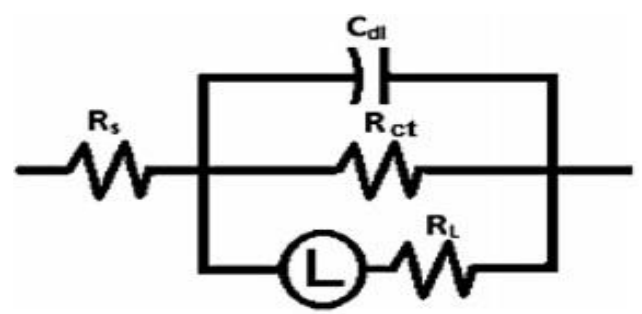

Figure 3. Simple circuit utilized to fit the EIS data.

Table 3. Results from electrochemical impedance tests for the dissolution of C-S in $1.0 \mathrm{M}$ hydrochloric acid at an altered dose of Conocarpus Erectus extract at $298 \mathrm{~K}$.

\begin{tabular}{l|c|c|c|c|c|c|c}
$\begin{array}{l}\text { Conc, } \\
\mathbf{p p m}\end{array}$ & $\begin{array}{c}\mathbf{R}_{\mathbf{S}}, \\
\mathbf{\Omega} \mathbf{c m}^{\mathbf{2}}\end{array}$ & $\mathbf{n}$ & $\begin{array}{c}\mathbf{Y}^{\mathbf{0}}, \\
\boldsymbol{\mu} \mathbf{\Omega}^{-\mathbf{1}} \mathbf{c m}^{-\mathbf{2}}\end{array}$ & $\begin{array}{c}\mathbf{R}_{\mathbf{c t}}, \\
\boldsymbol{\Omega} \mathbf{~ c m}^{\mathbf{2}}\end{array}$ & $\begin{array}{c}\mathbf{C}_{\mathbf{d l l}}, \\
\boldsymbol{\mu} \mathbf{F} \mathbf{~ c m}^{-\mathbf{2}}\end{array}$ & $\boldsymbol{\theta}$ & $\boldsymbol{\%} \mathbf{I E}$ \\
\hline Blank & 2.400 & 0.872 & 32.0 & 11.8 & 10.7 & ----- & ----- \\
\hline 50 & 4.788 & 1.034 & 8.184 & 29.9 & 8.7 & 0.605 & 60.5 \\
\hline 100 & 4.898 & 1.047 & 7.513 & 47.3 & 7.9 & 0.750 & 75.0 \\
\hline 150 & 4.527 & 1.021 & 7.260 & 65.3 & 7.3 & 0.819 & 81.9 \\
\hline 200 & 4.291 & 1.002 & 7.217 & 103.6 & 6.2 & 0.886 & 88.6 \\
\hline 250 & 4.432 & 0.997 & 6.763 & 112.9 & 5.8 & 0.895 & 89.5 \\
\hline 300 & 4.269 & 0.999 & 6.514 & 146.9 & 4.9 & 0.919 & 91.9
\end{tabular}

\subsection{Electrochemical frequency modulation (EFM) technique.}

EFM is characterized by speed and greater accuracy in calculating the current data [29]. Figure 4, "indicates the EFM of $\mathrm{Al}$ in $1.0 \mathrm{M} \mathrm{HCl}$ solution and existence of $300 \mathrm{ppm}$ dose of Conocarpus Erectus extract at $298 \mathrm{~K}$. The EFM parameters such as (CF-2 and CF-3), ( $\beta_{\mathrm{c}}$ and $\beta_{\mathrm{a}}$ ), and ( $\mathrm{i}_{\text {corr }}$ ) can be measured from the higher current peaks. The CF is closer to the standard data proved the validity of the calculated data [30]. The \% IE increased with the raising of Conocarpus Erectus extract and was calculated and listed Table 4; by increasing concentration of Conocarpus Erectus extract, the current density has a noticeable decrease, and hence \% IE increased". The IEEFM raised by improving the studied extract doses and was calculated as next:

$$
\% I E_{E F M}=\left(\frac{i_{\text {corr }}^{\circ} i_{\text {corr }}}{i_{\text {corr }}^{\circ}}\right) \times 100=\theta \times 100
$$

where $\mathrm{i}^{\mathrm{o}}$ corr and $\mathrm{i}_{\text {corr }}$ are corrosion current densities in the nonexistence and existence of Conocarpus Erectus extract, correspondingly 

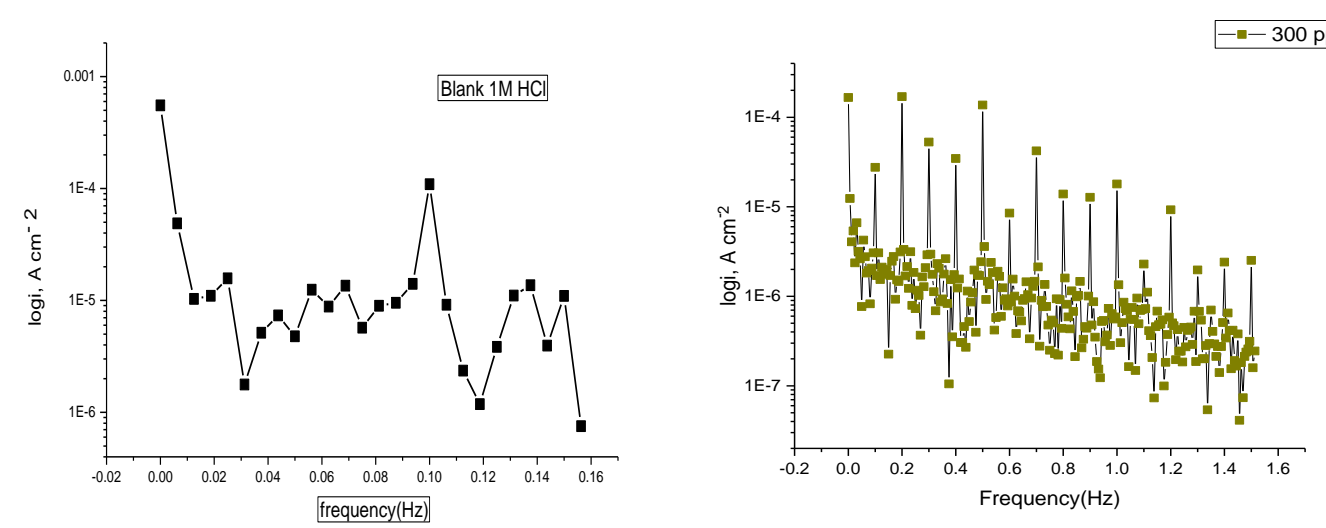

Figure 4. EFM curves for the dissolution of $\mathrm{Al}$ in $1 \mathrm{M} \mathrm{HCl}$ and in the existence of $300 \mathrm{ppm}$ Conocarpus Erectus extract at $298 \mathrm{~K}$.

Table 4. Parameters gained by EFM test for dissolution of $\mathrm{Al}$ in $1.0 \mathrm{M} \mathrm{HCl}$ solutions, including various doses of Conocarpus Erectus extract at $298 \mathrm{~K}$.

\begin{tabular}{|c|c|c|c|c|c|c|c|c|}
\hline $\begin{array}{l}\text { [inh], } \\
\text { ppm }\end{array}$ & $\begin{array}{c}\text { icorr } \\
\mathrm{mA} \mathrm{cm} \text { cm }^{-2}\end{array}$ & $\begin{array}{c}\beta_{a} \\
m V \operatorname{dec}^{-1}\end{array}$ & $\begin{array}{c}\beta_{\mathbf{c}} \\
\mathrm{mV} \operatorname{dec}^{-1} \\
\end{array}$ & $\begin{array}{c}\text { C.R x } \\
10^{-3} \mathrm{mpy}\end{array}$ & CF-2 & CF-3 & $\boldsymbol{\theta}$ & $\%$ IE \\
\hline Blank & 378.0 & 46 & 231 & 1.620 & 1.96 & 1.9 & ----- & ----- \\
\hline 50 & 257.9 & 40 & 46 & 1.106 & 1.98 & 1.83 & 0.317 & 31.7 \\
\hline 100 & 215.0 & 29 & 47 & 0.922 & 2.14 & 1.85 & 0.431 & 43.1 \\
\hline 150 & 139.2 & 28 & 49 & 0.597 & 2.23 & 1.89 & 0.632 & 63.2 \\
\hline 200 & 114.7 & 29 & 86 & 0.492 & 1.79 & 2.75 & 0.696 & 69.6 \\
\hline 250 & 111.0 & 29 & 85 & 0.476 & 1.78 & 2.72 & 0.706 & 70.6 \\
\hline 300 & 104.6 & 31 & 76 & 0.448 & 1.80 & 2.87 & 0.723 & 72.3 \\
\hline
\end{tabular}

\subsection{Weight loss (WL) technique.}

WL is one of the significant tests in defining the efficiency of the extract to inhibit the corrosion of $\mathrm{Al}$ metal. The experiments were conducted on altered doses of the Conocarpus Erectus extract in 1.0 M hydrochloric acid. "The whole experiment took three hours. Experiments were conducted at altered temperatures (298-318 K). Table 5 shows the results obtained in a time of 120 minutes of the research. We find that by increasing the dose from 50 ppm to $300 \mathrm{ppm}$, the rate of inhibition increases in contrast to the rate of corrosion, which decreases with increasing doses of Conocarpus Erectus extract. By increasing the temperature of the average, the \%IE will be raised, while there is a direct correlation with temperature with dose (Figs. 5 and 6). The corrosion rate of $\mathrm{Al}$ in the absence of Conocarpus Erectus extract increased steeply from 298 to 318 K, whereas; in the presence of Conocarpus Erectus extract, the corrosion rate decreased slowly. The rate of corrosion increases with an increase in temperature (Table 5) and hence, increases in \%IE as shown in Fig. 6. The increased inhibition of corrosion with an increased dose of Conocarpus Erectus extract can be attributed to the formation of a layer of the extract on the Al surface by adsorption". The layer formed of the adsorbed Conocarpus Erectus molecules isolates the surface of Al from the aggressive environment, which hindrance the dissolution of Al by blocking their corrosion sites [31].

\subsubsection{Kinetic and thermodynamic studies.}

In this examination, the effect of temperature on the corrosion of $\mathrm{Al}$ coins utilized in the Conocarpus Erectus extracted and dipped in $1.0 \mathrm{M}$ of hydrochloric acid was studied in the with and without altered doses of Conocarpus Erectus extract $(50-300$ ppm) at 298- $318 \mathrm{~K}$. The activation energy $\left(\mathrm{E}^{*}{ }_{\mathrm{a}}\right)$ measured from the slope of the diagrams utilized the Arrhenius Eq. (6) was used: 


$$
\log k_{\text {corr }}=\frac{-E_{a}^{*}}{2.303 R T}+\log A
$$

while the symbol (A) was utilized for the term exponential factor of Arrhenius. Arrhenius diagrams are illustrated in Fig. 7 [ $\log \mathrm{k}_{\text {corr }}$ against $\left.1 / \mathrm{T}\right]$, in which the energy of the activation is derived from the slopes of straight lines [- $\left.\mathrm{E}_{\mathrm{a}}^{*} / 2.303 \mathrm{R}\right]$. Using the transitional state equation, the changes in entropy and enthalpy were calculated.

$$
k_{\text {corr }}=\left(\frac{R T}{N h}\right) \exp \left(\frac{\Delta S^{*}}{R}\right) \exp \left(\frac{\Delta H^{*}}{R T}\right)
$$

Figure 8 Displays a plotting $\log \left(\mathrm{k}_{\mathrm{corr}} / \mathrm{T}\right)$ against 1000/T, "where this Figure shows the transitional state of the Conocarpus Erectus extract. Slopes are utilized to calculate enthalpy $\left(\left(-\Delta \mathrm{H}^{*} \mathrm{a} / 2.303 \mathrm{R}\right)\right.$, and the activation entropy of the shape is calculated utilizing intersections of the lines $\left[\log (\mathrm{R} / \mathrm{Nh})+\Delta \mathrm{S}^{*}\right.$ a/2.303R $] . \mathrm{E}^{*}$ a values increase in the presence of Conocarpus Erectus extract for $\mathrm{Al}$ in $1 \mathrm{M} \mathrm{HCl}$ (Table 6). The decrease in $\mathrm{E}_{\mathrm{a}}^{*}$ with increasing extract dose is typical of chemisorption due to the chemical bonds were strengthen by increasing temperature of energy barrier on the $\mathrm{Al}$ surface, and its thickness raises by improving the doses [32]. The $\left(\Delta \mathrm{H}^{*}\right.$ has a positive value that reflects the endothermic nature for the dissolution of Al. Normally, an endothermic procedure designates chemisorption". Reducing in the data of $\Delta S^{*}$ for the Conocarpus Erectus extract imply that activated complex in the rate-determining step signifies the dissociation rather than the association step, demonstrating that rise in disorder happened on going from reactants to the activated complex [33].

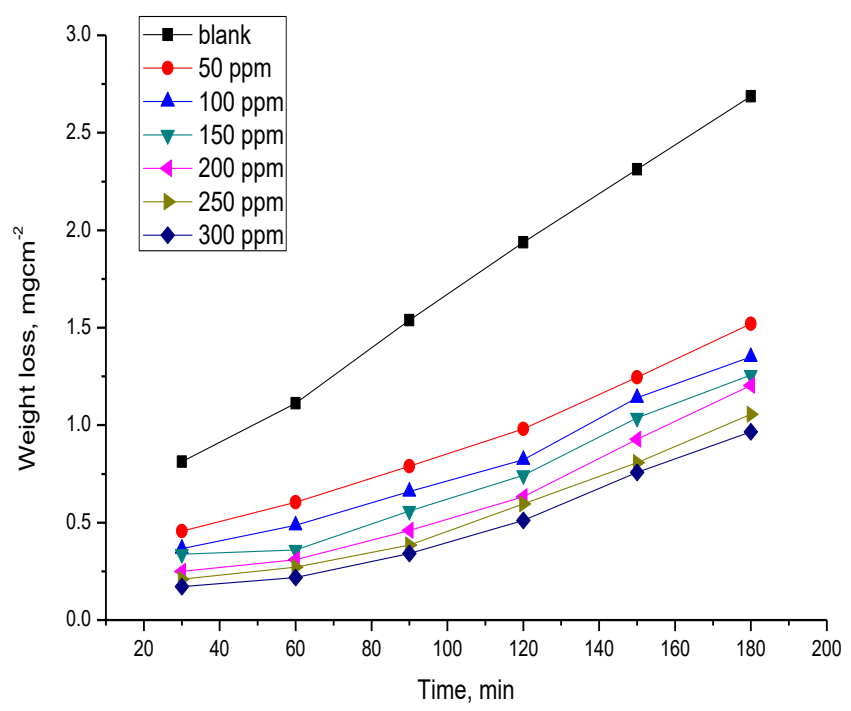

Figure 5. WL-time curves for the dissolution of $\mathrm{Al}$ in $1.0 \mathrm{M} \mathrm{HCl}$ at $298 \mathrm{~K}$, at altered doses of Conocarpus Erectus extract at $298 \mathrm{~K}$.

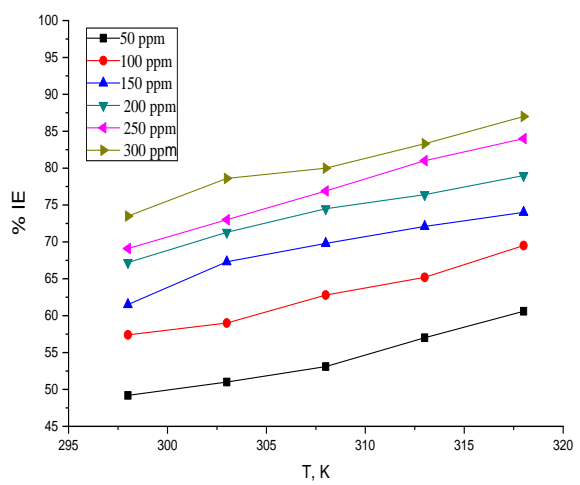

Figure 6. The influence of temperature on the \% IE of $\mathrm{Al}$ metal. 
Table 5. Data of $\mathrm{WL}$ of $\mathrm{Al}$ in $1.0 \mathrm{M} \mathrm{HCl}$ solution for various doses of Conocarpus Erectus after 120 min., at (298-318 K).

\begin{tabular}{|c|c|c|c|c|c|}
\hline Temp., K & $\begin{array}{c}\text { [Inh], } \\
\text { ppm }\end{array}$ & $\begin{array}{c}\mathrm{WL}, \\
\mathrm{mg} \mathrm{cm}^{2}\end{array}$ & $\begin{array}{c}\text { C.R.x10 } \\
\text { mg cm }^{2} \text { min }^{-1}\end{array}$ & $\boldsymbol{\Theta}$ & $\%$ IE \\
\hline \multirow{7}{*}{298} & Blank & 1.930 & 16.08 & -- & -- \\
\hline & 50 & 0.980 & 8.17 & 0.492 & 49.2 \\
\hline & 100 & 0.822 & 6.85 & 0.574 & 57.4 \\
\hline & 150 & 0.743 & 6.19 & 0.615 & 61.5 \\
\hline & 200 & 0.633 & 5.28 & 0.672 & 67.2 \\
\hline & 250 & 0.596 & 4.96 & 0.691 & 69.1 \\
\hline & 300 & 0.511 & 4.26 & 0.735 & 73.5 \\
\hline \multirow{7}{*}{303} & Blank & 3.96 & 33.0 & -- & -- \\
\hline & 50 & 1.94 & 16.17 & 0.510 & 51.0 \\
\hline & 100 & 1.62 & 13.53 & 0.590 & 59.0 \\
\hline & 150 & 1.29 & 10.75 & 0.673 & 67.3 \\
\hline & 200 & 1.13 & 9.42 & 0.713 & 71.3 \\
\hline & 250 & 1.06 & 8.83 & 0.730 & 73.0 \\
\hline & 300 & 0.84 & 7.00 & 0.786 & 78.6 \\
\hline \multirow{7}{*}{308} & Blank & 7.78 & 64.83 & -- & -- \\
\hline & 50 & 3.64 & 30.33 & 0.531 & 53.1 \\
\hline & 100 & 2.89 & 24.08 & 0.628 & 62.8 \\
\hline & 150 & 2.34 & 19.50 & 0.698 & 69.8 \\
\hline & 200 & 1.98 & 16.50 & 0.745 & 74.5 \\
\hline & 250 & 1.79 & 14.92 & 0.769 & 76.9 \\
\hline & 300 & 1.55 & 12.92 & 0.800 & 80.0 \\
\hline \multirow{7}{*}{313} & Blank & 19.11 & 159.25 & -- & -- \\
\hline & 50 & 8.21 & 68.40 & 0.570 & 57.0 \\
\hline & 100 & 6.65 & 55.40 & 0.652 & 65.2 \\
\hline & 150 & 5.33 & 44.42 & 0.721 & 72.1 \\
\hline & 200 & 4.50 & 37.50 & 0.764 & 76.4 \\
\hline & 250 & 3.63 & 30.25 & 0.810 & 81.0 \\
\hline & 300 & 3.19 & 26.58 & 0.833 & 83.3 \\
\hline \multirow{7}{*}{318} & Blank & 26.25 & 218.75 & -- & -- \\
\hline & 50 & 10.34 & 86.17 & 0.606 & 60.6 \\
\hline & 100 & 8.0 & 66.67 & 0.695 & 69.5 \\
\hline & 150 & 6.82 & 56.83 & 0.740 & 74.0 \\
\hline & 200 & 5.51 & 45.92 & 0.790 & 79.0 \\
\hline & 250 & 4.20 & 35.00 & 0.840 & 84.0 \\
\hline & 300 & 3.41 & 28.42 & 0.870 & 87.0 \\
\hline
\end{tabular}

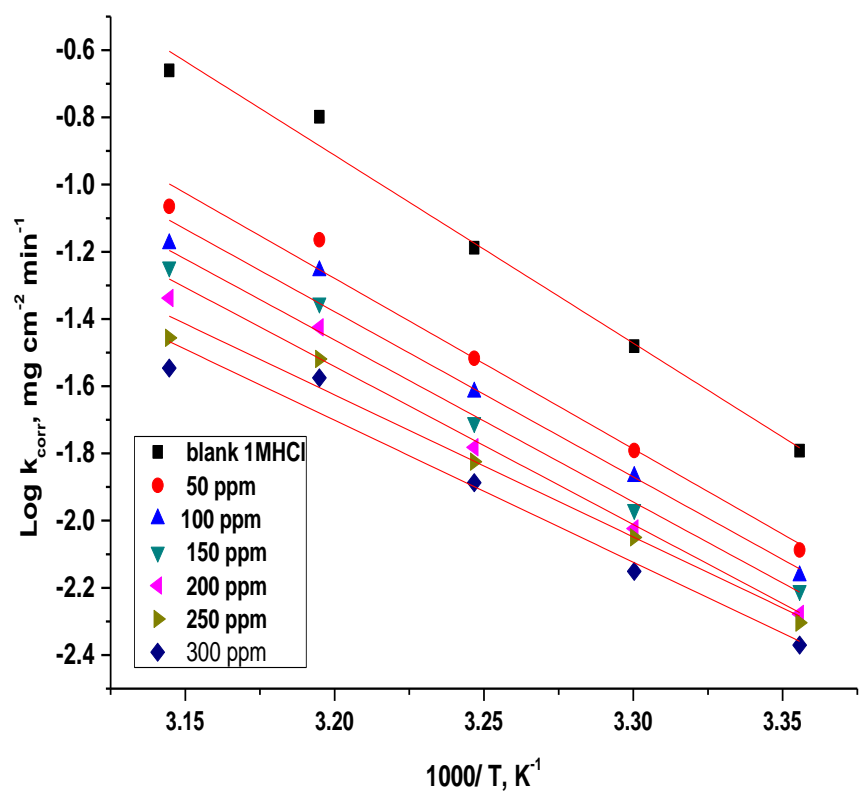

Figure 7. Arrhenius diagrams for dissolution of $\mathrm{Al}$ in $1.0 \mathrm{M} \mathrm{HCl}$ at altered doses of Conocarpus Erectus extract. 


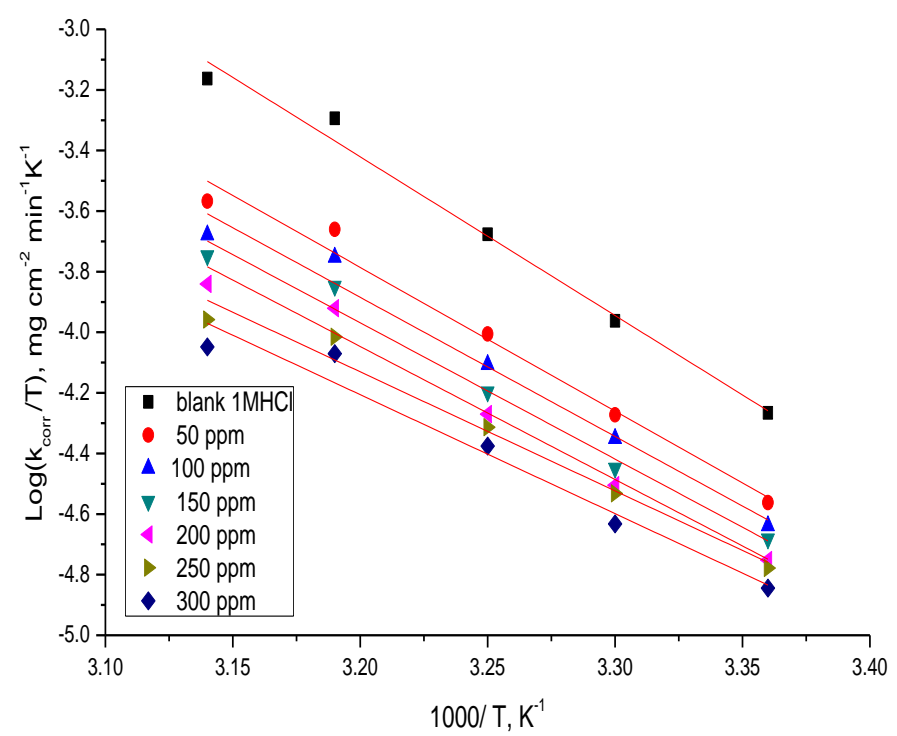

Figure 8. Transition state diagrams for dissolution of $\mathrm{Al}$ in $1.0 \mathrm{M} \mathrm{HCl}$ at altered doses of Conocarpus Erectus.

Table 6. Thermodynamic parameters of the Arrhenius equation and transition state equation.

\begin{tabular}{c|c|c|c}
$\begin{array}{c}{[\mathbf{i n h}],} \\
\mathbf{p p m}\end{array}$ & $\begin{array}{c}\mathbf{E a}^{*}, \\
\mathbf{k J ~ m o l}^{-\mathbf{1}}\end{array}$ & $\begin{array}{c}\Delta \mathbf{H}^{*}, \\
\mathbf{k J ~ m o l}^{\mathbf{1}}\end{array}$ & $\begin{array}{c}\Delta \mathbf{S}^{*}, \\
\mathbf{J ~ m o l}^{-1} \mathbf{K}^{-\mathbf{1}}\end{array}$ \\
\hline $1 \mathrm{M} \mathrm{HCl}$ & 107.0 & 105.0 & 74.0 \\
\hline 50 & 98.6 & 90.8 & 20.5 \\
\hline 100 & 94.1 & 87.5 & 9.5 \\
\hline 150 & 87.9 & 86.0 & 7.2 \\
\hline 200 & 85.3 & 83.7 & 4.8 \\
\hline 250 & 80.9 & 81.0 & 3.1 \\
\hline 300 & 61.0 & 78.4 & 1.4
\end{tabular}

\subsubsection{Adsorption isotherms.}

The behavior of adsorption of Conocarpus Erectus extract on the surface of $\mathrm{Al}$ can be described by adsorption isotherm. "Many adsorption processes can utilize, such as (Langmuir, Temkin, Freundlich, Flory-Huggins) [34]. It is deduced that $\theta$ increased with raising the extract dose; this is because of the adsorption of Conocarpus Erectus molecules on the Al surface. The excellent explanation of the adsorption procedure can be achieved by using Temkin isotherm". Equation 8 explains Temkin isotherm, and from it, we plot the linear relation between $\Theta$ and $\log$ C, which appears in (Fig. 9).

$$
\theta_{\text {coverage }}=\left(\frac{2.303}{a}\right) \log K_{a d s}+\left(\frac{2.303}{a}\right) \log C
$$

Where $\mathbf{C}$ refers to the dose of Conocarpus Erectus extract in the electrolyte, "a" (heterogeneous factor of $\mathrm{Al}$ surface) and $\mathrm{K}_{\mathrm{ads}}$ represents the equilibrium constant for the process of adsorption. The data gained from "a" $\mathrm{K}_{\mathrm{ads}}$ and $\Delta \mathrm{G}^{\circ}$ ads are obtained in Table 7. The relationship of $\mathrm{K}_{\mathrm{ads}}$ and standard free energy $\left(\Delta \mathrm{G}^{\circ}\right.$ ads $)$ can be expressed by Eq.9.

$$
\Delta G^{\circ}{ }_{a d s}=-R T \ln \left(55.5 K_{a d s}\right)
$$

In this equation, the value 55.5 reveals the water concentration in the bulk solution where it is expressed in $\mathrm{mol} / \mathrm{L}$. " $\Delta \mathrm{G}^{\circ}$ ads had negative values designates spontaneous adsorption of the Conocarpus Erectus extracts molecules on the surface of Al. Therefore, $\Delta \mathrm{G}^{\circ}$ ads were determined (37.3-47.4 $\left.\mathrm{kJ} \mathrm{mol}^{-1}\right)$ and recorded in Table $7, \Delta \mathrm{G}^{\circ}$ ads data up to $\left(-20 \mathrm{~kJ} \mathrm{~mol}^{-1}\right)$ is reliable with physisorption while that more than $\left(-40 \mathrm{~kJ} \mathrm{~mol}^{-1}\right)$ defines chemisorption mechanism. $\mathrm{K}_{\mathrm{ads}}$ values increase with a rise in temperature (Table 8), indicative that the strength between adsorbate and adsorbent [35]. This also supports the chemical mechanism than the physical mechanism (i.e., mixed adsorption mechanism); the heterogeneous factor of 
metal surface $(\mathrm{a}>0)$ positive value shows that there is a molecular attraction between the adsorbed molecules on a metal surface". Also, an endothermic adsorption process $\left(\Delta \mathrm{H}^{\circ}\right.$ ads $\left.>0\right)$ may involve chemisorption [36]. The plot of $\left(\Delta \mathrm{G}^{\mathrm{o}}\right.$ ads $)$ versus $\mathrm{T}$ as shown in (Fig.10) conferring to the basic thermodynamic equation:

$$
\Delta G_{\mathrm{ads}}^{\circ}=\Delta H_{\mathrm{ads}}^{\circ}-T \Delta S_{\mathrm{ads}}^{\circ}
$$

In our research, the value of $\Delta \mathrm{H}^{\mathrm{o}}$ ads equals $98 \mathrm{~kJ} \mathrm{~mol}^{-1}$, which designates that the adsorption is chemisorption. Large negative value $\Delta \mathrm{S}_{\text {ads }}^{\mathrm{o}}=-454 \mathrm{~J} \mathrm{~mol}^{-1} \mathrm{~K}^{-1}$ indicates that lowering in a disorder of dissolution process on the surface of $\mathrm{Al}$ in $1 \mathrm{M} \mathrm{HCl}$ utilizing Conocarpus Erectus extract as a corrosion inhibitor (Table 7).

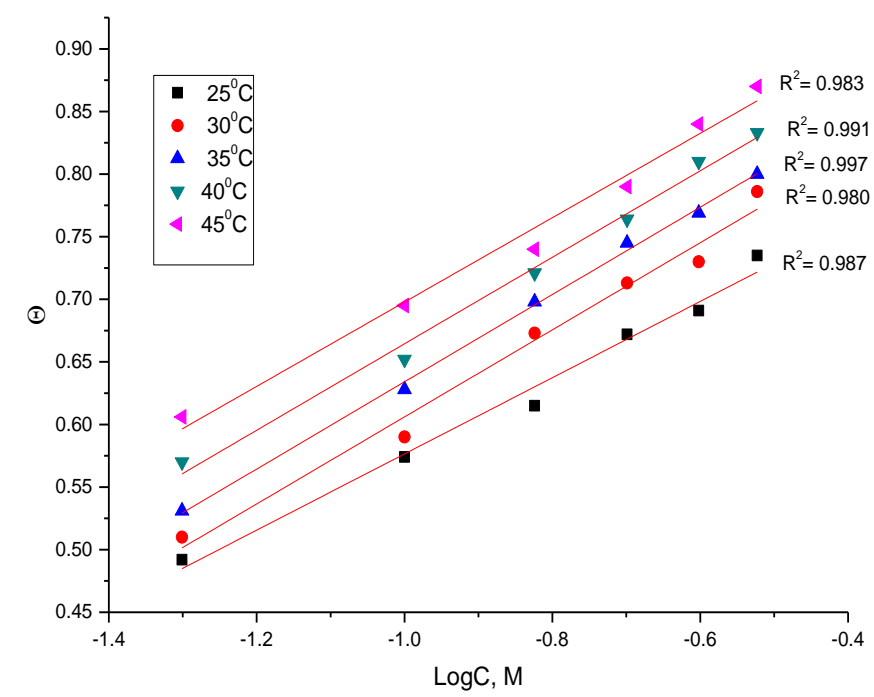

Figure 9. Temkin isotherms for $\mathrm{Al}$ dissolution in $1 \mathrm{M} \mathrm{HCl}$ at altered temperatures.

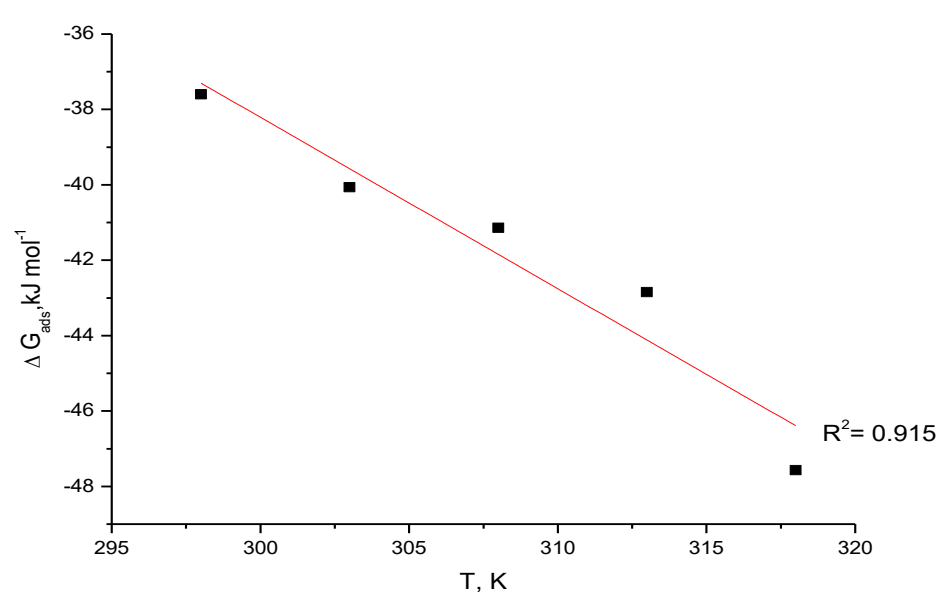

Figure 10. Variation of $\Delta \mathrm{G}^{\mathrm{o}}$ ads versus $\mathrm{T}$ for the adsorption of Conocarpus Erectus on $\mathrm{Al}$ surface in $1 \mathrm{M} \mathrm{HCl}$.

Table 7. Parameters for Temkin adsorption of Conocarpus Erectus on Al surface at various temperatures.

\begin{tabular}{|c|c|c|c|c|c|}
\hline $\begin{array}{c}\text { Temperature, } \\
\text { K } \\
\end{array}$ & $\mathbf{a}$ & $\begin{array}{c}\log K_{\text {ads }} \\
M^{-1} \\
\end{array}$ & $\begin{array}{c}-\Delta \mathbf{G}^{\mathbf{0}} \text { ads } \\
\mathbf{k J} \mathbf{~ m o l}^{-1}\end{array}$ & $\begin{array}{r}\Delta \mathbf{H}^{\mathbf{0}}{ }^{\mathrm{ads}} \\
\mathrm{kJ} \mathrm{mol}^{-1}\end{array}$ & $\begin{array}{c}-\Delta \mathbf{S}_{\text {ads }}^{\mathbf{0}} \\
\mathbf{J}^{\mathbf{m o l}^{-1} \mathbf{K}^{-1}} \\
\end{array}$ \\
\hline 298 & 7.96 & 4.80 & 37.3 & \multirow{5}{*}{98.0} & \multirow{5}{*}{454.0} \\
\hline 303 & 8.29 & 5.16 & 40.0 & & \\
\hline 308 & 7.41 & 5.23 & 41.1 & & \\
\hline 313 & 7.54 & 5.40 & 42.8 & & \\
\hline 318 & 8.03 & 6.05 & 47.4 & & \\
\hline
\end{tabular}

3.5. Surface characterization by scanning electron microscopy (SEM). 
SEM affords a pictorial representation of the Al surface. "The micrographs of $\mathrm{Al}$ specimens with and without 300 ppm of Conocarpus Erectus extract after 24 hours dipping in 1.0 M hydrochloric acid were shown in Fig. 11(a, b, c) The SEM micrographs of polished Al (free) in Fig. 11a showed the smooth surface of the Al. This shows the lack of any damage products or extracts complex designed on the Al surface. The SEM micrograph of Al surface immersed in $\mathrm{HCl}$ is shown in Fig. 11b. The damage of the $\mathrm{Al}$ surface designates that the dissolution of $\mathrm{Al}$ in $\mathrm{HCl}$. Fig.11c indicates that in the presence of $300 \mathrm{ppm}$ in $\mathrm{HCl}$, that we have no cracks and the surfaces of the specimens are more smooth rather than without using the extract; this is because of the random arrangement of the Conocarpus Erectus molecules on the surface of the Al", and a with attaching the active sites on the Al surface and making protection of the $\mathrm{Al}$ from the corrosive medium via the extract [37].

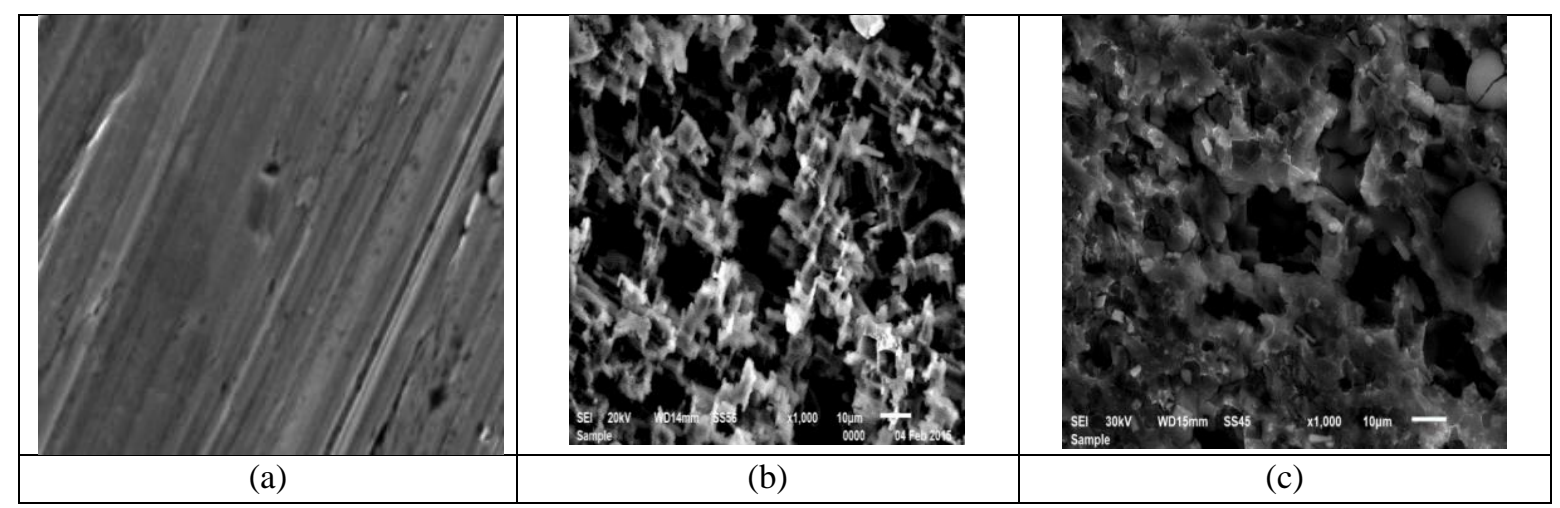

Figure 11. SEM micrographs of $\mathrm{Al}$ samples after immersion in $1 \mathrm{M} \mathrm{HCl}$ for 24 hours at $298 \mathrm{~K}$. (a) without Conocarpus Erectus extract and $\mathrm{HCl}$ (b) with dipping in $1 \mathrm{M} \mathrm{HCl}$, and (c) after $24 \mathrm{~h}$ dipping in $1 \mathrm{M} \mathrm{HCl}+300$ ppm of Conocarpus Erectus extract.

\subsection{Comparison of inhibition efficiency achieved from altered tests.}

Table 8 reports the comparison of \%IE gotten from various tests (WL, PP, EIS, and EFM measurements) for $\mathrm{Al}$ in $1 \mathrm{M} \mathrm{HCl}$ solution at altered doses of Conocarpus Erectus extract at $298 \mathrm{~K}$. The outcomes data obtained from all tests were in excellent agreement, as revealed in Fig 12.

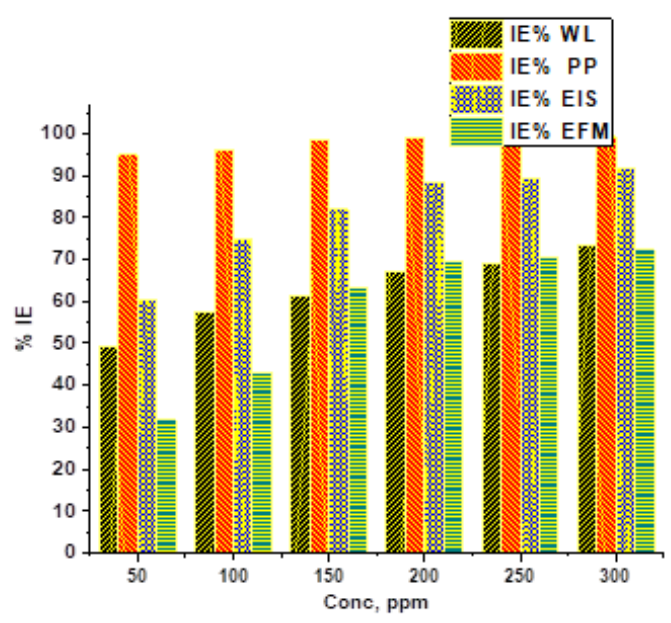

Figure 12. Inhibition efficiency obtained from WL, PP, EIS, and EFM measurements for Al dissolution in $1 \mathrm{M}$ $\mathrm{HCl}$ at different doses of Conocarpus Erectus extract at $298 \mathrm{~K}$. 
Table 8. \% IE obtained from WL, PP, EIS and EFM tests for Al dissolution in $1 \mathrm{M} \mathrm{HCl}$ at altered doses of Conocarpus Erectus extract at $298 \mathrm{~K}$.

\begin{tabular}{c|c|c|c|c}
\multirow{2}{*}{$\begin{array}{c}{[\mathbf{I n h}]} \\
\mathbf{p p m}\end{array}$} & WL & PP & EIS & EFM \\
\cline { 2 - 5 } & 49.2 & 94.9 & 60.5 & 31.7 \\
\hline 50 & 57.4 & 96.2 & 75.0 & 43.1 \\
\hline 100 & 61.5 & 98.3 & 81.9 & 63.2 \\
\hline 150 & 67.2 & 98.8 & 88.6 & 69.6 \\
\hline 200 & 69.1 & 99.2 & 89.5 & 70.6 \\
\hline 250 & 73.5 & 99.3 & 91.9 & 72.3
\end{tabular}

\subsection{Mechanism of corrosion inhibition.}

Conocarpus Erectus extract is included various naturally taking place in organic composites. "Hence, the protected action of Conocarpus Erectus extract could be qualified to the adsorption of its constituents on the surface of Al. The main phytochemical components of this plant extract are seventeen compounds representing Tannins, Flavonoids (Rhamnetin), Coumarins, and Triterpenes (Celastrol) were the major constituents in the plant. The presence of heteroatoms such as $\mathrm{N}$ and $\mathrm{O}$ directly attached to the aromatic ring improves the obtainability of $\pi$-electrons to get bonded to the vacant p-orbital of Al. The great control of Conocarpus Erectus extract could also be due to the big size of this Conocarpus Erectus molecule, which coated varied areas on the surface of $\mathrm{Al}$ and hence, prevents the dissolution. In the case of the neutral form of the Conocarpus Erectus extract molecules, adsorption occurs through the replacement of water molecules adsorbed on a metal surface and the sharing of electrons between heteroatoms of extract molecules and the Al surface. Moreover, extract molecules can adsorb to the metal on the base of the donor-acceptor interaction between the vacant p-orbitals of $\mathrm{Al}$ surface atoms and the $\pi$ electrons of benzene rings, which lead to a rise in the thickness of the formed layer on the $\mathrm{Al}$ surface by formation of coordination bonds with the heteroatoms present in the main components (chemical adsorption)". It was found that the Al surface in acid media has a positive charge, which leads to a coordination bond with the negative charge species (physical adsorption) [38]. In an aqueous acidic environment, the main constituents of Conocarpus Erectus extract may exist as neutral molecules or as protonated molecules (cations). So, in view of the above mechanism, the following may occur: First $\mathrm{Cl}^{-}$anions adsorb chemically on positively charged $\mathrm{Al}$ surface, resulting in that the Al surface became negatively charged. The protonated extract molecules then get adsorbed on the negatively charged Al surface, forming a physisorption mechanism.

\section{Conclusions}

The results obtained from all tests displayed that the hindrance action rises with increases in the Conocarpus Erectus extract doses and with improving the solution temperature (chemical adsorption). Raising the dose of the Conocarpus Erectus extract reduced the double layer capacitances and increasing the $\mathrm{R}_{\mathrm{ct}}$. The adsorption of plant extract molecules on the $\mathrm{Al}$ surface follows Temkin adsorption isotherm. The adsorption negative free energy $\left(-\Delta \mathrm{G}^{\circ}{ }_{\text {ads }}\right)$ suggests fast and spontaneous adsorption of the extracts on the surface of Al, and chemisorption was found to be the adsorbed of the Conocarpus Erectus extract. Tafel polarization results indicate that this extract component act as a mixed-kind inhibitor but more cathodic. The inhibition efficiencies determined by WL, PP, EFM, and EIS tests are the best agreement. SEM micrographs indicate that this extract is adsorbed on the $\mathrm{Al}$ surface, forming a protective film. 


\section{Funding}

This research received no external funding.

\section{Acknowledgments}

All our gratitude to the anonymous referees for their careful reading of the manuscript and valuable comments which helped in shaping this paper to the present form. We thank all laboratory staff of corrosion chemistry from the University of Mansoura (Egypt) and Umm AlQura University (Saudi Arabia) for their kind cooperation.

\section{Conflicts of Interest}

The authors declare no conflict of interest.

\section{References}

1. Chaubey, N.; Savita; Singh, V.K.; Quraishi, M.A. Corrosion inhibition performance of different bark extracts on aluminum in alkaline solution. J. Assoc. Arab Univ. Basic Appl. Sci. 2017, 22, 38-44, https://doi.org/10.1016/j.jaubas.2015.12.003.

2. Raghavendra, N. Green Compounds to Attenuate Aluminum Corrosion in $\mathrm{HCl}$ Activation: A Necessity Review. Chemistry Africa 2020, 3, 21-34, https://doi.org/10.1007/s42250-019-00114-6.

3. Onukwuli, O.D.; Ezeugo, J.O. Plant extract as biodegradable inhibitor, for zinc in dilute solution of sulphuric acid. World Scientific News 2018, 109, 195-210.

4. Umoren, S.A.; Obot, I.B.; Israel, A.U.; Asuquo, P.O.; Solomon, M.M.; Eduok, U.M.; Udoh, A.P. Inhibition of mild steel corrosion in acidic medium using coconut coir dust extracted from water and methanol as solvents. J. Ind. Eng. Chem. 2014, 20, 3612-3622, https://doi.org/10.1016/j.jiec.2013.12.056.

5. Deng, S.; Li, X. Inhibition by Jasminum nudiflorum Lindl. leaves extract of the corrosion of aluminum in HCl solution. Corros. Sci. 2012, 64, 253-262, https://doi.org/10.1016/j.corsci.2012.07.017.

6. Raghavendra, N.; Hublikar, L.V.; Patil, S.M.; Ganiger, P.J.; Bhinge, A.S. Efficiency of sapota leaf extract against aluminum corrosion in a $3 \mathrm{M}$ sodium hydroxide hostile fluid atmosphere: a green and sustainable approach. Bulletin of Materials Science 2019, 42, https://doi.org/10.1007/s12034-019-1922-1.

7. Oguzie, E.E.; Onuchukwu, A.I.; Okafor, P.C.; Ebenso, E.E. Corrosion inhibition and adsorption behavior of Ocimum basilicum extract on aluminum. Pigment \& Resin Technology 2006, 35, 63-70, https://doi.org/10.1108/03699420610652340.

8. Anbarasi, C.M.; Divya, G. A green approach to corrosion inhibition of aluminum in acid medium using azwain seed extract. Materials Today: Proceedings 2017, 4, 5190-5200, https://doi.org/10.1016/j.matpr.2017.05.026.

9. Njoku, C.N.; Bai, W.; Arukalam, I.O.; Yang, L.; Hou, B.; Njoku, D.I.; Li, Y. Epoxy-based smart coating with self-repairing polyurea-formaldehyde microcapsules for anticorrosion protection of Al alloy AA2024. Journal of Coatings Technology and Research 2020, 17, 797-813, https://doi.org/10.1007/s11998-02000334-3.

10. Kasuga, B.; Park, E.; Machunda, R. Inhibition of Aluminum Corrosion Using Carica papaya Leaves Extract in Sulphuric Acid. Journal of Minerals and Materials Characterization and Engineering 2018, 06, 1-14, https://doi.org/10.4236/jmmce.2018.61001.

11. Arora, P.; Kumar, S.; Sharma, M.K.; Mathur, S.P. Corrosion inhibition of Aluminum by Capparis deciduas in Acidic Media. E-Journal of chemistry 2007, 4, https://doi.org/10.1155/2007/487820.

12. Deng, S.; Li, X. Inhibition by Jasminum nudiflorum Lindl. leaves extract of the corrosion of aluminum in HCl solution. Corros. Sci. 2012, 64, 253-262, https://doi.org/10.1016/j.corsci.2012.07.017.

13. Madufor, I.C.; Itodoh, U.E.; Obidiegwu, M.U.; Nwakaudu, M.S.; Aharanwa, B.C. Inhibition of aluminum corrosion in acidic medium by chrysophyllum albidum (African star apple) fruit extract. Journal of Engineering 2012, 2, 16-23, https://doi.org/10.9790/3021-02951623.

14. Umoren, S.A.; Eduok, U.M.; Israel, A.U.; Obot, I.B.; Solomon, M.M. Coconut coir dust extract: a novel ecofriendly corrosion inhibitor for $\mathrm{Al}$ in $\mathrm{HCl}$ solutions. Green Chem. Lett. Rev. 2012, 5, 303-313, https://doi.org/10.1080/17518253.2011.625980.

15. Loto, C.A.; Popoola, A.P.I. Plants extracts corrosion inhibition of aluminum alloy in H2SO4. Canadian Journal of Pure and Applied Sciences 2012, 6, 1973-1980.

16. Shalabi, K.; Fouda, A.S.; Elewady, G.Y.; El-Askalany, A. Adsorption and inhibitive properties of Phoenix dactylifera L. Extract as a green inhibitor for aluminum and aluminum-silicon alloy in $\mathrm{HCl}$. Protection of 


Metals and Physical Chemistry of Surfaces 2014, 50, 420-431,
https://doi.org/10.1134/S2070205114030174.

17. Loto, C.A.; Joseph, O.O.; Loto, R.T. Adsorption and inhibitive properties of Camellia Sinensis for aluminium alloy in HCI. International Journal of Electrochemical Science 2014, 9, 3637-3649.

18. Geetha, S.; Lakshmi, S.; Bharathi, K. Solanumtrilobatum as a green inhibitor for aluminium corrosion in alkaline medium. Journal of Chemical and Pharmaceutical Research 2013, 5, 195-204.

19. Bharathi, K.; Lakshmi, S.; Geetha, S. Inhibitive effect of Morindacitrifolia L. leaves extract on aluminium corrosion in HCL medium. Journal of Chemical and Pharmaceutical Research 2013, 5, 187-194.

20. Yadav, S.; Choudhary, G.; Sharma, A. Green approach to corrosion inhibition of aluminium and copper by Ziziphusauritiana fruit extract in hydrochloric acid solution. International Journal of ChemTech Research 2013, 5, 1815-1823.

21. Petchiamma, A.; Selvaraj, S. The corrosion control of aluminium using Lawsoniainermis seed extract in acid medium. International Journal of ChemTech Research 2013, 5, 1566-1574.

22. Raghavendra, N.; Bhat, J.I. Natural Products for Material Protection: An Interesting and Efficacious Anticorrosive Property of Dry Arecanut Seed Extract at Electrode (Aluminum)-Electrolyte (Hydrochloric Acid) Interface. Journal of Bio- and Tribo-Corrosion 2016, 2, https://doi.org/10.1007/s40735-016-0051-2.

23. Motawea, M. M.; El-Hossiany, A.; Fouda, A.S. Corrosion Control of Copper in Nitric Acid Solution using Chenopodium Extract. Int. J. Electrochem. Sci. 2019, 14, 1372-1387, https://doi.org/10.20964/2019.02.29.

24. Fouda, A.S.; Abd El-Maksoud, S.A.; El-Hossiany, A.; Ibrahim, A. Evolution of the Corrosion-inhibiting Efficiency of Novel Hydrazine Derivatives against Corrosion of Stainless Steel 201 in Acidic Medium. Int. J. Electrochem. Sci. 2019, 14, 6045-6064, https://doi.org/10.20964/2019.07.65.

25. Chaubey, N.; Singh, V.K.; Quraishi, M.A. Electrochemical approach of Kalmegh leaf extract on the corrosion behavior of aluminium alloy in alkaline solution. International Journal of Industrial Chemistry 2017, 8, 75-82, https://doi.org/10.1007/s40090-016-0103-y.

26. Fouda, A.S.; Abd El-Maksoud, S.A.; El-Hossiany, A.; Ibrahim, A. Effectiveness of Some Organic Compounds as Corrosion Inhibitors for Stainless Steel 201 in $1 \mathrm{M} \mathrm{HCl}$ : Experimental and Theoretical Studies. Int. J. Electrochem. Sci. 2018, 13, 9826 - 9846, https://doi.org/10.20964/2018.10.36.

27. Abdallah, M.; Kamar, E.M.; Eid, S.; El-Etre, A.Y. Animal glue as green inhibitor for corrosion of aluminum and aluminum-silicon alloys in sodium hydroxide solutions. Journal of Molecular Liquids 2016, 220, 755761, https://doi.org/10.1016/j.molliq.2016.04.062.

28. Fouda, A.S.; Eissa, M.; El-Hossiany, A. Ciprofloxacin as Eco-Friendly Corrosion Inhibitor for Carbon Steel in Hydrochloric Acid Solution. Int. J. Electrochem. Sci. 2018, 13, 11096-11112, https://doi.org/10.20964/2018.11.86.

29. Li, X.; Deng, S.; Li, N.; Xie, X. Inhibition effect of bamboo leaves extract on cold rolled steel in $\mathrm{Cl} 3 \mathrm{CCOOH}$ solution. Journal of Materials Research and Technology 2017, 6, 158-170, https://doi.org/10.1016/j.jmrt.2016.09.002.

30. Fouda, A.S.; Rashwan, S.; Kamel, M.M.; Arman, N.M. Adsorption and Inhibition Behavior of Avicennia Marina for Zn Metal in Hydrochloric Acid Solution. International Journal of Electrochemical Science 2017, 12, 11789-11804, https://doi.org/10.20964/2017.12.95.

31. Fouda, A.S.; Ismael, M.A.; Abo Shahba, R.M.; Kamel, L.A.; El-Nagggar, A.A. Corrosion Inhibition of Copper and $\alpha$-Brass in $1 \mathrm{M}$ HNO3 Solution using New arylpyrimido [5, 4-c] quinoline-2,4-dione derivative. Int. J. Electrochem.Sci. 2017, 12, 3361-3384, https://doi.org/10.20964/2017.04.57.

32. Lebrini, M.; Lagrenée, M.; Vezin, H.; Traisnel, M.; Bentiss, F. Experimental and theoretical study for corrosion inhibition of mild steel in normal hydrochloric acid solution by some new macrocyclic polyether compounds. Corros. Sci. 2007, 49, 2254-2269, https://doi.org/10.1016/j.corsci.2006.10.029.

33. Baymou, Y.; Bidi, H.; Ebn Touhami, M.; Allam, M.; Rkayae, M.; Belakhmima, R.A. Corrosion Protection for Cast Iron in Sulfamic Acid Solutions and Studies of the Cooperative Effect Between Cationic Surfactant and Acid Counterions. Journal of Bio- and Tribo-Corrosion 2018, 4, https://doi.org/10.1007/s40735-0180127-2.

34. Fouda, A.S.; Abd El-Maksoud, S.A.; El-Hossiany, A.; Ibrahim, A. Corrosion Protection of Stainless Steel 201 in Acidic Media using Novel Hydrazine Derivatives as Corrosion Inhibitors. Int. J. Electrochem. Sci. 2019, 14, 2187-2207, https://doi.org/10.20964/2019.03.15.

35. Nadi, I.; Belattmania, Z.; Sabour, B.; Reani, A.; Sahibed-dine, A.; Jama, C.; Bentiss, F. Sargassum muticum extract based on alginate biopolymer as a new efficient biological corrosion inhibitor for carbon steel in hydrochloric acid pickling environment: Gravimetric, electrochemical and surface studies. International Journal of Biological Macromolecules 2019, 141, 137-149, https://doi.org/10.1016/j.ijbiomac.2019.08.253.

36. Devi, P.N.; Sathiyabama, J.; Rajendran, S. Study of surface morphology and inhibition efficiency of mild steel in simulated concrete pore solution by lactic acid-Zn2+ system. International Journal of Corrosion and Scale Inhibition 2017, 6, 18-31, https://doi.org/10.17675/2305-6894-2017-6-1-2.

37. Singh, A.K.; Quraishi, M.A. Investigation of the effect of disulfiram on corrosion of mild steel in hydrochloric acid solution. Corros. Sci. 2011, 53, 1288-1297, https://doi.org/10.1016/j.corsci.2011.01.002. 
38. Fouda, A.S.; Abdel Azeem, M.; Mohamed, S.A.; El-Hossiany, A.; El-Desouky, E. Corrosion Inhibition and Adsorption Behavior of Nerium Oleander Extract on Carbon Steel in Hydrochloric Acid Solution. Int. J. Electrochem. Sci. 2019, 14, 3932-3948, https://doi.org/10.20964/2019.04.44. 